\title{
TECHNICAL WORKER'S PARTICIPATION IN THE CVET AND COMPANY COMPETITIVENESS
}

\author{
Eduardo Figueira \\ CISA-AS ${ }^{1}$, University of Évora \\ Évora / Portugal \\ figueira@uevora.pt \\ Timothy Koehnen \\ CETRAD ${ }^{2}$, University of Trás-os-Montes and Alto Douro \\ Vila Real / Portugal \\ tkoehnen@utad.pt \\ Vítor Rosa \\ CISA-AS, University of Évora \\ Évora / Portugal \\ vitor.rosa@mail.pt \\ Ana Cordeiro \\ CETRAD, University of Trás-os-Montes and Alto Douro \\ Vila Real / Portugal \\ acordeiro@utad.pt \\ António Fragoso \\ $\mathrm{CIEO}^{3}$, University of Algarve \\ Faro / Portugal \\ aalmeida@ualg.pt \\ Rogério Roque Amaro \\ $\mathrm{CIES}^{4}$, Superior Institute for the Sciences of Work and Business \\ Lisboa / Portugal \\ rogerio.amaro@iscte.pt \\ Filipe Ribeiro \\ CISA-AS, University of Évora \\ Évora / Portugal \\ flipjribeiro@hotmail.com \\ Lídia Tomé \\ CISA-AS, University of Évora \\ Évora / Portugal \\ lidiap tome@hotmail.com \\ Mónica Aldeia \\ CISA-AS, University of Évora \\ Évora / Portugal \\ monica.aldeia@gmail.com
}

\footnotetext{
1 (CISA-AS) Centre for Research in Sociology and Anthropology - "Augusto da Silva".

2 (CETRAD) Centre for Transdisciplinary Development Studies.

${ }_{3}^{3}$ (CIEO) Centre for Research on Space and Organizations.

${ }^{4}$ (CIES) Centre for Research and Sociological Studies.
} 


\begin{abstract}
The present study intends to understand how factors influence employed adults' decision to participate in learning activities in two sectors of the five regions (NUT II) of the Portuguese continental territory. The factors associated to individuals' participation in Continuing Vocational Education and Training (CVET) constitute an important issue to be studied given the need to understand why adults participate in CVET activities. This is important because continuing professional qualification of workers is assumed to be essential to improve workers' employability and productivity in companies. In fact, the level of productivity of business depends on effective use of new technologies which is only possible with human resources continuously qualified. For this reason, results will allow us to elaborate recommendations for designing and implementing policies for CVET activities. The present research will be using a methodological approach framed by the ISSTAL (Interdisciplinary, SequentialSpecificity, Time-Allocation, Life-Span) model of social participation (Smith, 1980), already adapted and tested in USA by Cookson (1986) and in Alentejo and other EU regions by Figueira \& others (2008) for studying adult participation in learning activities. The study will use a cross-sectional survey complemented by a focus group strategy to discuss survey results by continuing training specialists and practitioners and by a set of case studies to further understanding nature of the participation factors. The cross-sectional survey will use an instrument specifically developed to collect data from a two-stage stratified random sample drawn from a population constituted by technical working people of the two main sectors in the above Portuguese continental regions. According to results from previous studies, it will be expected that the ISSTAL model will be useful for explaining and understanding participation of adults in continuing training activities concerning the sectors of activity under analysis. The study will give an important contribution for promoting equal access to CVET for all workers, as a relevant pathway for a sustainable development of the Portuguese society.
\end{abstract}

Keywords - Participation, competitiveness, continuing education and training, SME's

\title{
INTRODUCTION
}

The present paper describes work conducted in CVET activities in Portuguese Small and Medium Enterprises (SMEs). The study intends to identify and understand workers' participation in learning activities in the main sectors of activity in the Portuguese continental territory: industries of metal (except machinery and equipment), stone, agro-food and drinks, and furniture. Financed by the Science and Technology Foundation of the Portuguese Ministry of Science, the study is being conducted by a team of researchers from four universities who are interested to know why and how technical workers participate in learning activities. The study believes that the workers participate in these activities assuming 'involvement' and 'investment' forms, that are, in the double sense of psychoanalysis and economic, as referred to by Bourdieu (1994).

The factors that influence the participation of workers in continuous training are not totally known in Portugal. Nevertheless, it constitutes an important question to be studied given that the existing 'ideas' about the subject are not exempt from some unfounded speculation, or an absence of scientific research. For this reason, the understanding of the nature of factors associated to participation of workers in continuous education constitutes an important base for human resource development policy and strategy formulation for different social-vocational groups. This understanding is also important to define policies and strategies to organize the continuous educational systems, seeking to adapt the nature of the training supply and demand. In addition, the reasons why adults participate in CVET will permit the implementation of strategies to make the working population aware of the importance of CVET activities, not only in social and professional terms but also in their quality of life. Continuous qualification of vocational workers is assumed to be essential for improving both the employability of workers and organizational productivity and, consequently, it is important for promoting local development.

[In a society both knowledge-based and dynamic, in which knowledge and abilities are always in danger of becoming obsolete unless they are constantly renewed and updated, permanent involvement in CVET is increasingly becoming a necessity for the workforce] (Brown et al., 2004: 7).

The continuous qualification of human resources represents a condition 'sine qua non' to increase the entrepreneurial efficacy. In this light of reasoning, it plays an essential role for economic progress and social development of a nation (Houtkoop \& Kamp, 1992; Reich, 1992). In fact, the entrepreneurial effectiveness depends on individuals' level of productivity and this depends upon the efficient and effective use of new technologies, which, in turn, becomes possible with continuous qualified human resources. In addition, this problem is directly related to the workers' capacity to adapt to rapid changes that occur in the employment market. On one side, this paradigm requires the workers' 
predisposition to update their vocational competencies during their life and, on the other side, increasing the participation of technical workers in continuous education constitutes one of the relevant strategies to prevent economic and social exclusion. In addition, promoting participation in continuous education, for those who are out of the labour market (mainly who are less qualified), will contribute to the social inclusion of the less favoured members of the population.

\section{STATE OF THE ART IN CVET}

The research about participation of adults in continuing education has been based upon two assumptions: first, learning for adults is essentially a voluntary activity, and secondly the characteristics of adults and their reasons for participation in training will vary (Houtkoop and Kamp, 1992). However, the 'social mechanisms' (using an expression of Bourdieu, 1980) that regulate and/or are associated to the workers position prior to the possibility of participation in the process of continuing training are still not well known. Given the training availability throughout life, the reality has shown that the individuals have a multiplicity of attitudes that brings a certain complexity to the phenomenon. This problem originates, through practical terms, such as conception and implementation difficulties for continuous vocational training programs to satisfy individuals' needs and employment entities' interests, in particular, and social-economic development, in general.

The CVET can be seen as subsequent (training/learning) programme offering, throughout active life, following the initial education/training programmes. CVET allows for the improvement of active population' skills and competencies, widening knowledge and capacity of individuals to deal with different activities. In this way, CVET facilitates adult individuals to adapt to organisational, technical, and technological transformations in context of today. In addition, the importance of the CVET has become a determining factor for the competitiveness of countries, regions and companies. According to previous studies, active adults, who participate in training/educational activities, are, mainly, young individuals with technical jobs, belonging to the medium/high social-economic status and having secondary or higher education (Brunner, Wilder, Kierchner and Newberry, 1959). Individuals' level of formal education appears to be a relevant factor for participation in continuing vocational training. In spite of the temporal distance, results from those studies appear to be in line with the present reality, or at least, very close to the situation found in less favored regions of Europe (Brown, Grollmann, Tutschner and Participa Project Consortium, 2004).

Understanding factors influencing participation of active adults in training is very relevant for designing and implementing strategies of continuing education programmes aiming to adapt training supply that reflect training demands for continuing qualification of professionals. This is true because understanding how and why adults participate (or not) in CVET activities facilitates setting up and implementing effective strategies to promote continuing education programmes to satisfy training needs of individuals and organisations.

Active adults' attitude toward to continuing and systematic learning processes and factors associated to their resistance to participation in continuing education are not well known. Factors associated with adult' participation in CVET activities are of diverse nature. According to previous research results, adult's participation in education is influenced by characteristics of personal order and contextual nature. The personal factors are usually associated to individual's experience in social and educational processes. For instance, most of the active adults who participate in training activities have a technical profession and/or belongs to high social status (Brunner, Wilder, Kircher and Newberry, 1959). Furthermore, individuals' level of formal education appeared to be very positively associated with their participation in continuing education. Although carried out in 1950s, that study achieved results that appear to be very close to the situation of the less developed European regions. The contextual factors are related to characteristics of environment and conditions of training offerings. In addition, the difference between adults' participation and non-participation appears to lie in aspects associated to age, school level, and residence (Johnstone and Riviera, 1965). The location of the training activities and the need to learn may also pose obstacles to an individual's participation in training activities. For instance, place where training activities are going to be held is often revealed by non-participants as an important barrier.

The issues determining adults' non-participation in educational activities have been the focus of many authors such as Cross (1981), Darkenwald and Merriam (1982), and Darkenwald and Valentine (1985). In fact, adult educators have been very much interested in the phenomenon of adult participation in continuing education, mainly concerning factors that influence that participation and how this participation can be predicted (Yang, Blunt, \& Butler, 1994). Although participation in continuing education have been very much studied, few conceptual models have been useful for predicting participation of adults in training activities (Yang, Blunt, \& Butler, 1994). Many researchers 
have framed their participation studies by Fishbein and Ajzen (1975) behavioural intention model. Others have tried to link motivation with participation in training activities (Houle, 1961; Boschier, 1971; Bourgess, 1971; Morstain and Smart, 1974; Grotelueschen and Caulley, 1977). Some other researchers have based their studies on the social psychology theory (Boshier, 1971; Cross, 1981; Darkenwald and Merriam, 1982). Still others, such as Tuijman and Fagherlind (1989), defend the existence of three key-points regarding the factors influencing participation in adult education: (1) Sociological, characterised by demographic variables such as age, gender, education, social roles, social position and home-background; (2) Psychological, addressing personality traits, intellectual capacity and attitudinal disposition; and (3) Economic, which plays a small part in the research concerning the participation of adults in training activities. Nevertheless, other conceptual models propose to explain adults' participation in CVET activities from a broader theoretical perspective instead of emphasising the association between participation and motivation or attitude. In fact, research carried out more recently have posted new questions and have opened other research perspectives for studying adult participation in training activities. For example, factors related to marketing of continuing education offerings, social context of individuals, difficulties of personal and professional order, in addition to individuals' motivation appear to influence decision of adults for taking training (Van Tilbourg, 1989). Additionally, a typology for non-participants in continuing education has been developed by using a set of criteria composed by personal difficulties, lack of confidence, financing costs, lack of interest for formal educational activities (Darkenwald and Valentine, 1990).

Some specialists try to relate motivation and/or adult attitudes with participation in training activities (Houle, 1961; Boschier, 1971; Bourgess, 1971; Morstain and Smart, 1974; Grotelueschen and Caulley, 1977). Others base their research on social-psychological theories (Boshier, 1971; Cross, 1981; Darkenwald and Merriam, 1982). Nevertheless, recent studies open different research perspectives and accentuate new problems. In a more systematic way, Cookson (1986) has been studying the participation of adults in learning activities based on the adaptation of a social participation model known by ISSTAL (Interdisciplinary, Sequential-Specificity, Time-Allocation, LifeSpan), developed by Smith (1980). According to Cookson (1986) and Brown (2005), the adapted ISSTAL model seems to serve as a good theoretical model for studying and analyzing the relationships between individual and organizational characteristics and the participation of workers in learning activities. In fact, the ISSTAL model presents three characteristics, of particular importance, for theory and research about active adult participation in continuous vocational training: first, a conceptual and interdisciplinary research framework; second, a specific sequential relationship between participation and independent variables; and, third, a perspective of the time distribution during the individual life. In addition to this, the analysis of worker participation during a time period permits the identification of factor-patterns that influence participation (Gorard, 1998). In fact, [(...) ISSTAL provides a more comprehensive understanding of the broader psychological, structural, and cultural contexts affecting adult participation in learning. This model attempts to incorporate all relevant variables to present an interdisciplinary understanding of adult participation in learning. The model considers external contextual variables, social background and social role variables, personality traits and intellectual capacities, attitudinal dispositions (values, attitudes, expectations, intentions), retained information (images, beliefs, knowledge, plan), and situational variables (immediate awareness and definition of the situation)] (Smith \& Theberge, 1987: 6).

The model postulates individual and discretionary adult behaviour resulting from a complex interaction among a set of predictive (independents) variables organised into six subsets (Cookson, 1986): (1) External context, (2) social background, (3) personality, (4) attitudinal dispositions, (5) retained information, and (6) situational aspects.

Based on the above considerations, the ISSTAL model appears to be adequate to analyze technical workers' participation in CVET activities, in Portugal (Brown, Grollmann, Tutscher and Participa Project Consortium, 2004).

\section{MAIN GOALS OF THE STUDY}

The main goal of the research project is to identify, analyse and understand the factors associated to participation in CVET by workers with technical functions in SME in Portugal. The evaluation and characterization of attitudes of those workers, concerning their participation in actions related to continuous vocational training, could give an important contribution for defining and adjusting adequate strategies to increase effectiveness and efficiency of training programs, as well as promoting participation of technical workers in their own professional valorisation and vocational qualification. 
Therefore, this study intends to understand and investigate one of the more important key mechanisms in the social integration of participation for technicians in continuous training.

The study intends to achieve, more specifically, the following objectives:

- Identify and analyse the factors associated to the participation of technical workers in continuous training activities and understand how it influences the decision to participate or not;

- Analyse and characterize the attitude of technical workers faced with their own participation in continuous training programs;

- Contribute to the definition and implementation of policies and strategies that promote and increase the participation of these workers in continuous training programs;

- Contribute to a better understanding, definition and implementation of training strategies throughout life that strengthens the capacity to attain employment or self-employment;

- Contribute to the definition and implementation of policies and strategies for the development of human resources, in respect to the promotion of entrepreneurial competitivity in the less favoured regions in Europe;

- Develop a participation model that capacitates political decision-makers and educators to improve their approach to continuous training with the knowledge of workers, managers and entrepreneurs.

\section{RESEARCH PROCEDURES AND METHODOLOGY}

According to the complexity of the phenomenon under investigation, the study object and the purposes have led to the construction of a model for analysis combining different research methods and techniques used in social sciences involving the triangulation approach. Specifically, the study has been conducted following six phases: 1) Review of the literature to elaborate the "state of the art" related to participation of adults in continuous training activities; 2) "Desk research" related to the productive sector activities in which they occur in the study for each of the regions with a special incidence to the question of worker participation in continuous training activities; 3) Conducting a "cross sectional survey" with a random and stratified sample per region of the target population; 4) Treatment, analysis, and interpretation of collected information through an interview by questionnaire; 5) Conducting a Focus Group to investigate deeply the captured information from the questionnaire (the Focus Group are a specific type of group interview in which information is collected not only from the statements of participants but also from the interactions of participants who are encouraged to present their opinions and comments on the opinions of others); 6) Conducting a case-study (one for each of the regions) to improve the understanding of the obtained results in proceeding phases. For this project we are interested in examining the case of a "successful" company in the development of VET participation procedures for its employees. For the construction of the case study we will collect data from conversations with employees, from interviews with directors of the company and from examination of written reports prepared by the company.

The first phase was oriented to up-dating the literature review, initiated with the project proposal and later complemented by an analysis of research studies conducted in each region in order to enrich the state of the art. The second phase had consisted in choosing the target productive sectors based on in their expressivity in terms of regional identity Gross Domestic Product (GDP). The third phase has involved the elaboration, testing and application of the survey questionnaire to a target group composed by a representative number of technical workers selected in each region following a stratified random sample strategy. The first draft of the questionnaire was based on a version used in previous similar research studies conducted in Portugal and was adjusted after the results and observations from the pre-test. Results from pre-test have indicated that the scales included in the instrument have a high reliability based on the Alpha Cronbach Coefficient (min: 0,766; max: 0,872). The questionnaires have been applied in a direct or indirect form, in function to the specific characteristics of each company and region. The fourth phase consists in the treatment, analysis and interpretation of the captured information through the questionnaires. A Focus Group will be conducted in the fifth phase with the purpose to deepen interpretation of the collected data from the survey phase. The focus group will be constituted by 6 to 10 elements representing policy-makers, trainers and/or other training practitioners, entrepreneurs, union representatives from the studied sectors and trainees. The sixth phase will encompass a case-study in each of the regions and the dissemination by a final conference. Data from the case-study will be collected through semi- 
structured interviews and non-participant observation. The case-study will be fundamentally seen as a means to complement results from the earlier phases to increase understanding of the participation phenomenon in CVET. The case-study will be based on SME chosen using a specific criterion established after the survey.

After all these procedures, results will be analysed over-all and by each region and studied sector, having a view to understand the phenomenon in its whole dimension and how characteristics of the different regional and sectoral contexts may eventually influence the participation in CVET. For this purpose, comparisons among the five regions and the studied sectors will be made.

\section{PRELIMINARY RESULTS OF THE SURVEY}

\subsection{Target characterization}

The preliminary results of the survey conducted so far in the regions of the North, Centre and Alentejo has shown the following. At the moment, we have 998 cases. As shown in Graphic 1, 74\% ( $n=730)$ of all respondents were male and $26 \%(n=253)$ are female workers.

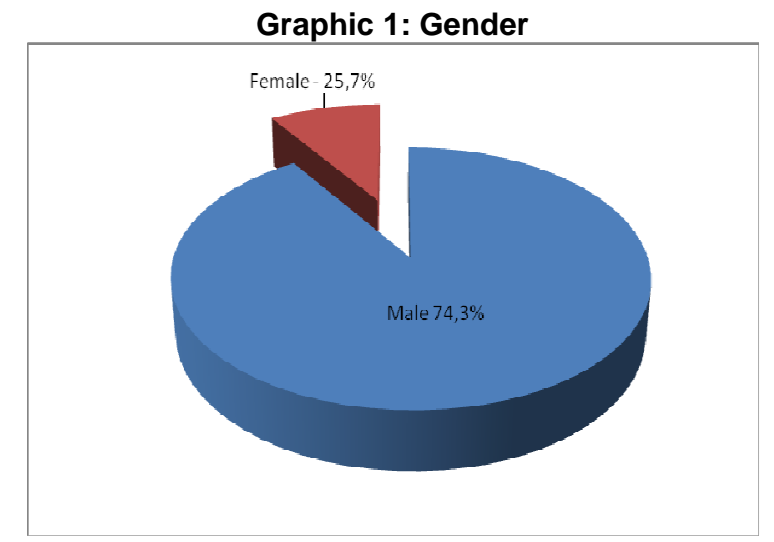

Observing all workers of the sample, we can see that their mean age is 38 year-old. The workers range is 57 years expanding between 17 and 74 year-old. In another measure, the median is 38 , which tell us that fifty per cent of these workers have up to 38 years-of age, and the other fifty per cent have greater than 38 years. The modal value (the number which appears most often) is 38 year-old (see Table 1).

Table 1: Descriptives - Age

\begin{tabular}{|c|c|c|c|}
\hline & & Statistic & Std. Error \\
\hline Mean & & 38,32 & 0,349 \\
\hline \multirow{2}{*}{$\begin{array}{l}95 \% \text { Confidence Interval for } \\
\text { Mean }\end{array}$} & Lower Bound & 37,63 & - \\
\hline & Upper Bound & 39,00 & - \\
\hline $5 \%$ Trimmed Mean & & 38,12 & - \\
\hline Median & & 38,00 & - \\
\hline Variance & & 116,278 & - \\
\hline Std. Deviation & & 10,783 & - \\
\hline Minimum & & 17 & - \\
\hline Maximum & & 74 & - \\
\hline Range & & 57 & - \\
\hline Interquartile Range & & 16 & - \\
\hline Skewness & & 0,265 & 0,079 \\
\hline Kurtosis & & $-0,617$ & 0,158 \\
\hline
\end{tabular}

Taking into account the academic and vocational qualifications, only $76 \%$ of the respondents have completed primary education. However, $6.3 \%$ of the respondents have not completed secondary 
education and only $3.5 \%$ have completed vocational or technological preparation. Finally, it should be mentioned that only $7.1 \%$ of workers from our sample have a higher educational degree (see Table 2).

Table 2: Academic and Vocational Qualifications

\begin{tabular}{lcc}
\hline \hline & Frequency & Percent \\
\hline Elementary -1st & 278 & 28,3 \\
Elementary - 2nd & 266 & 27,1 \\
Primary school - 3rd & 201 & 20,5 \\
Secondary school incomplete & 62 & 6,3 \\
Secondary school complete & 69 & 7,0 \\
Professional school complete & 25 & 2,5 \\
Tecnhological education complete & 10 & 1,0 \\
Superior education & 70 & 7,1 \\
\hline \multicolumn{1}{c}{ Total } & $\mathbf{9 8 1}$ & $\mathbf{1 0 0 , 0}$ \\
\hline \hline
\end{tabular}

The average (central tendency of a data set) of monthly income of the household for the respondents, is essentially $€ 1500$ (93\%), 53\% received a monthly income less than $€ 1000$ and $40 \%$ between $€$ 1001 and $€ 1500$ (see Graphic 2).

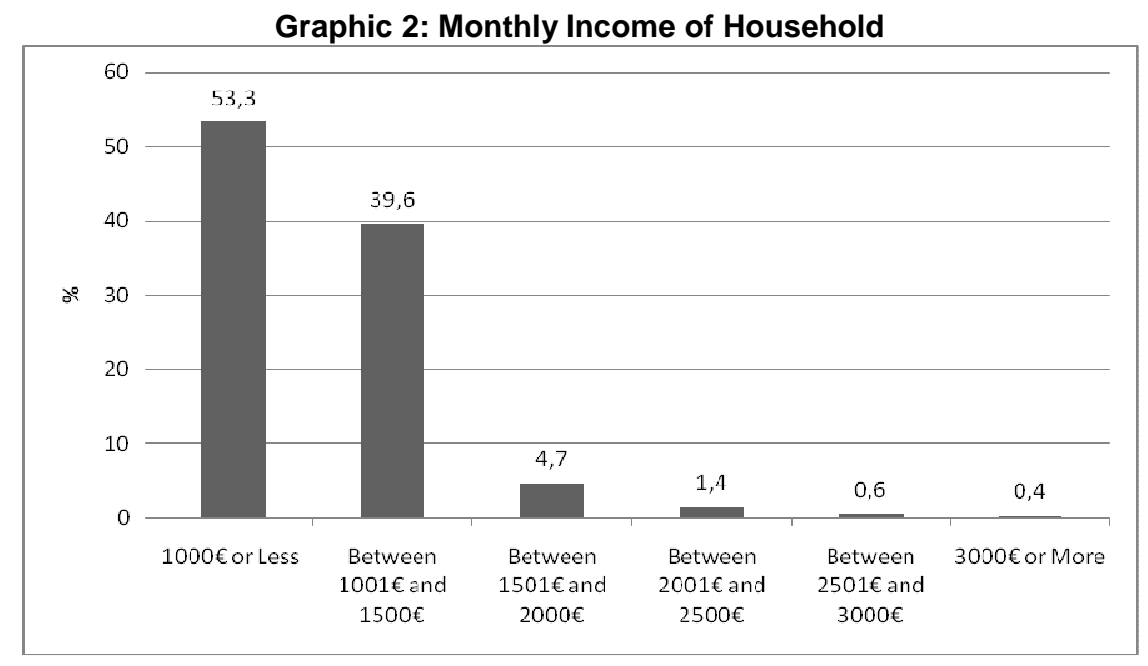

\subsection{Reasons for participation and non-participation in training course}

See Table 3 to answer the question "Do you have already attended vocational training courses?". This Table shows that $39 \%$ of the inquired never participated in vocational training courses. Another interesting aspect it is that $36 \%$ of the inquired of this sample participated in vocational training courses only after having started an occupation. As it also shows exists a low percentage of workers that have dropped out.

Table 3: Do you have already attended vocational training courses?

\begin{tabular}{|c|c|c|}
\hline & Frequency & Percent \\
\hline Never attended & 388 & 39,3 \\
\hline I attended but I dropped out & 52 & 5,3 \\
\hline I attended after having started an occupation & 357 & 36,1 \\
\hline I attended before having started an occupation & 83 & 8,4 \\
\hline I attended before and after having started an occupation & 94 & 9,5 \\
\hline Total & 974 & 98,6 \\
\hline NR & 14 & 1,4 \\
\hline Total & 988 & 100,0 \\
\hline
\end{tabular}


Regarding the reasons that leads to the non-participation of respondents in continuing training offerings, the output with the Friedman statistics test shows that "training time as incompatible with the working hours" $(6,50)$, "do not have time to spare" $(6,07)$ and "there are other things with greater priority in my life" $(6,04)$ and are the most influential characteristics. On the other hand, the "frequency of these courses affect my family life" is one of the reasons that receive the lowest ranking, on the option by the respondents to not participate in the training courses (see Table 4).

Table 4: Reasons of non-participation in training course

\begin{tabular}{lc}
\hline \hline \multicolumn{1}{c}{ Reasons } & Mean Rank \\
\hline The schedules of the courses are incompatible with my work & 6,50 \\
Do not have time to spare & 6,07 \\
There are other things more priority in my life & 6,04 \\
Be difficult to reconcile with my family life & 5,67 \\
Do not want to sacrifice the little free time I have & 5,55 \\
The location of the training course do not satisfy me & 5,38 \\
De difficult to find someone to replace me at work & 5,33 \\
Do not like to go alone for training courses & 5,21 \\
Not be willing or interest & 4,68 \\
The frequency of these courses affect my family life & 4,62 \\
\hline \hline
\end{tabular}

In the case of the attitudes and reasons for participation in continuing training, it appears that are the "need to learn" $(7,35)$, "create new job opportunities" $(7,26)$ and "an opportunity to make new friends" $(7,07)$ that weighs more in the decision to participate in the training courses. "Having a child" $(4,35)$ is one that has less influence in this subject (see Table 5).

Table 5: Reasons to participation in training course

\begin{tabular}{lr}
\hline \hline \multicolumn{1}{c}{ Reasons } & Mean Rank \\
\hline Feeling the need to learn & 7,35 \\
Participation in training can create new job opportunities & 7,26 \\
Participation in training is an opportunity to make new friends & 7,07 \\
Lifelong learning is fundamental to keep me updated professionally & 7,01 \\
Need to continue in my career & 6,53 \\
Feel the need to be recognized professionally & 6,40 \\
Have time available & 5,90 \\
Having the need to participate as a volunteer at one institution & 4,87 \\
My friends have convinced me of the importance of the attending training & 4,64 \\
Founding a family & 4,62 \\
Having had a child & 4,35 \\
\hline \hline
\end{tabular}

\section{FINAL CONSIDERATIONS}

CVET can be seen as important for subsequent training activities, planned throughout active life, and following initial education. It aims to improve people's skills and competencies, widening knowledge of individuals or promoting their specialization at a specific level. The CVET facilitates adults to adapt to organizational, technical and technological transformations. Taking in consideration the study purpose and its objectives, and the results from previous studies, the study may allow proposing the following contributions:

- Adopting new CVET policies that include strategies for promoting, participation in continuing learning activities;

- Offering of more attractive continuous training programs to stimulate participation;

- Understanding the importance for employed technical workers and managers of human resources to promote CVET throughout life; 
- Adding value for technical workers in terms of higher qualification and better performance which will be translated into career progression and remunerative benefits, justifying the investment in training;

- Increasing productivity in SMEs by strengthening individuals' qualification as a result from participation in CVET.

Policies for promoting quality in CVET should be developed and there is a need to integrate incentives to make employers and employees aware of the role of training for job performance and the need for self-directed learning in addition to participation in CVET offers.

In data of UTAD we found that the employer (small family business) did not value training and felt that it would contribute to mobility.

\section{References}

[1] Boschier, R. (1971), "Motivational orientations of adult education participants: a factor analytic exploration of Houle's typology", in Adult Education, 21, pp. 3-26.

[2] Bourdieu, P. (1980), Questions de Sociologie, Paris, Minuit.

[3] Bourdieu, P. (1994), Raisons Pratiques - Sur la Théorie de L'Action, Paris, Seuil.

[4] Bourgess, P. (1971), "Reasons for adult participation in group educational activities", in Adult Education, 21, pp. 3-29.

[5] Brown, A. (ed.) (2005), Learning while working in small companies: comparative analysis of experiences drawn from England, Germany, Greece, Italy, Portugal and Spain, SKOPE Monograph N ‥ 7, ESRC funded Centre on Skills, Knowledge and Organisational Performance, Oxford and Warwick Universities.

[6] Brown, A.; Grollmann, P.; Tutschner \& PARTICIPA Project Consortium (2004), Participation in Continuing Vocational Educational and Training: Results from the Regional and Sectoral Surveys, Bremen, Universität Bremen.

[7] Brunner, E., Wilder, P., Kierchner, C., \& Newberry, J. (1959), "An overview of adult education research", in Adult Education Quartely, Vol. 10, n. 1, 56-58.

[8] Cookson, P. (1986), "A framework for theory and research on adult education participation", in Adult Education Quarterly, (36), 3, pp. 130-141.

[9] Cross, P. (1981), Adults as Learners: Increasing Participation and Facilitating Learning, San Francisco, Jossey-Bass Publisher.

[10]Darkenwald, G. \& Merriam, S. (1982), Adult Education: Foundations of Practice, New York, Harper and Row.

[11] Darkenwald, G. \& Valentine, T. (1985), Factor structure of deterrents to public participation in adult education, in Adult Education Quarterly, 35, pp. 177-193.

[12] Darkenwald, G. \& Valentine, T. (1985), Outcomes of in adult basic skills education. Lifelong Learning: An Omnibus of Practice and Research, 8(5), pp. 17-22.

[13] Figueira, E., Entonado, F. \& Lucero, M. (2008), "Participation of Employed Adults in Continuing Training Activities. The cases of the Agrofood Industry in Alentejo (Portugal) and of the Building Sector in Extremadura (Spain)". Paper presented in European Research Conference, "Local in Global Adult Learning and Community Development”, Wroclaw, Poland, 29-31 May. 
[14]Figueira, E., Silva, S. \& Rainha, L. (2004), "Participação na formação contínua: uma necessidade para uma empregabilidade sustentável na Região do Alentejo", in Actas do V Congresso Português de Sociologia, sob o título "Sociedades Contemporâneas: Reflexividade e Acção", pp. 39-43.

[15] Figueira, E.; Koehnen, T.; Rosa, V.; Cordeiro, A.; Aldeia, M.; Fragoso, A. \& Amaro, R. (2009), "Relationship between SMEs' technical worker's participation in the CVET and company competitiveness: the case of Portugal". Paper presented in III International Seminar ESREA Network Between Global and Local - Adult Learning and Development, "Local Development, community and adult learning, learning landscapes between the mainstream and the margins", Madgeburk, Germany, 28-30 May.

[16] Fishbein, M. \& Ajzen, I (1975), Understanding attitudes and predicting social behaviour, New Jersey, Prentice-Hall.

[17] Gorard, S. (1998), "Reflections of the past: the generation of school choice", in Education Today, 48, pp. 25-32.

[18] Groteluescgen, A \& Caulley, D (1977), "A model for studying determinants of intentions to participate in continuing professional education", in Adult Education, Vol. 28, oㅜ 1, pp. 22-37.

[19] Houle, C. (1961), The inquiring mind, Madison, University of Wisconsin Press.

[20] Houtkoop, W. \& Van der Kamp, M. (1992), "Factors influencing participation in continuing education", in International Journal of Educational Research, 17, 6, pp. 537-547.

[21] Johnstone J. W. C. \& Rivera, R. J. (1965), Volunteers for learning: A study of the educational pursuits of adults, Hawthorne, NY: Aldine.

[22] Morstain, B. \& Smart, J. (1974), "Reasons for participation in adult education courses: a multivariate analysis of group differences", in Adult Education, 24, pp. 83-98.

[23] Reich, R. (1992), The Work of Nations, New York, Vintage Books.

[24] Smith, D. \& Theberge, Nancy (1987), Why people recreate: an overview of research, Campaingn, IL, Life Enhancement Publications.

[25] Smith, D. (1980), "General activity model", in Participation in Social and Political Activities, D. H. Smith, J. Macanlay and Associates (eds.), S. Francisco, Jossey Bass, pp. 461-530.

[26] Tuijnman, A., Fagerland, I. (1989), "Measuring and predicting in lifelong in education using longitudinal data ", in Scandinavian Journal of Educational Research (33), 1, pp. 47-46.

[27] Van Tilbourg, Emmalou (1989), "Participation and persistence in continuing lifelong learning experiences of the Ohio Cooperative Extension Service: an investigation using expectancy valence". Journal of Agricultural Education, (30), 4, 42-46.

[28] Yang, B., Blunt, A., \& Butler, R. (1994), "Prediction of participation in continuing professional education: A test of two behavioural intention models", in Adult Education Quarterly, (44), 2, pp. 83-96. 